\title{
I CAN'T RELAX! YOU'RE DRIVING ME QUASI!
}

BY

\section{STEPHEN INGRAM}

\begin{abstract}
Robust Realists think that there are irreducible, non-natural, and mind-independent moral properties. Quasi-Realists and Relaxed Realists think the same, but interpret these commitments differently. Robust Realists interpret them as metaphysical commitments, to be defended by metaphysical argument. Quasi-Realists and Relaxed Realists say that they can only be interpreted as moral commitments. These theories thus pose a serious threat to Robust Realism, for they apparently undermine the very possibility of articulating the robust metaphysical commitments of this theory. I clarify and respond to this threat, showing that there is in fact space to develop and defend a robust moral ontology.
\end{abstract}

\section{Introduction}

There are a number of ways to be a realist about morality, but many realists these days accept the following combination of commitments:

Truth. There are substantive moral truths.

Properties. Substantive moral truths are truths about the moral properties of certain acts or types of act.

Non-Reductivism. Moral properties are not reducible to descriptive properties.

Non-Naturalism. Moral properties are beyond the purview of the natural and social sciences.

Mind-Independence. Moral properties are not constitutively dependent on any agent's or set of agent's actual or hypothetical responses to those properties, or to the world. 
It will be convenient to give this combination of commitments a name, so I'll call them the 'Realist Commitments.'

My aim is to show that the Realist Commitments can be construed as robustly metaphysical. Many philosophers have rejected this possibility by suggesting that they can only be articulated and defended or rejected from within the first-order moral perspective. This is the view taken by 'QuasiRealists' and 'Relaxed Realists' about morality. ${ }^{1}$ There are important differences between these positions, but philosophers in both camps agree that the Realist Commitments can only be understood as 'internal' to the moral domain. Others deny this, however. According to 'Robust Realists,' accepting the Realist Commitments requires a certain ontological seriousness. ${ }^{2}$ They are metaphysical commitments that we should understood as 'external' to morality. Robust Realists, Relaxed Realists, and Quasi-Realists do agree on certain points - they all accept the Realist Commitments - but they disagree on whether these commitments should be interpreted as internal moral claims or external metaphysical claims.

Importantly, if Relaxed Realists and Quasi-Realists are right to say that the Realist Commitments can only be construed as internal moral claims, this is a problem for Robust Realists. After all, if there's no way to give an external metaphysical reading of the Realist Commitments, there's no space for a robust moral ontology. I intend to show that that Robust Realism survives this threat. I explore the nature of the challenge to Robust Realism in \$2, expanding on the distinction between claims that are 'internal' and 'external' to morality. In $\S 3$ I consider a modest version of the challenge, focusing on Blackburn's early formulation of Quasi-Realism. My remarks here are brief, for I'm more interested in an ambitious version of the challenge posed by Relaxed Realism. I discuss this in $\$ 4$, concluding in $\$ 5$ by claiming that, whether or not Robust Realism is true, there is at least space for such a theory.

\section{Two anti-Archimedean challenges}

What puts the 'Robust' in Robust Realism? I suggest the following, which offers an ontologically serious interpretation of the Realist Commitments:

External Metaphysics. We can discuss the Realist Commitments from an external metaphysical standpoint, and the tenability of those commitments is to be assessed primarily from that standpoint by appeal to metaphysical argumentation.

Relaxed Realists and Quasi-Realists reject External Metaphysics. They say that the Realist Commitments only make sense from an internal moral perspective, and that the tenability of these commitments is to be assessed primarily from that perspective by appeal to moral argument. This is what 
makes Relaxed Realism and Quasi-Realism non-robust. They think it impossible to articulate the ontology that Robust Realists accept, and in this sense they imply that there isn't even space for Robust Realism. It is worth exploring the nature of this challenge further because, as I'll explain, there are two versions of it. I'll begin by clarifying what is meant by talk of an 'internal' and an 'external' perspective.

The internal perspective is the point of view at which we ask substantive ethical questions. It is the first-order moral perspective, and is called 'internal' because it is the standpoint occupied within the moral domain. In other words, it is the perspective from which one judges that killing is wrong and that courage is a virtue. These first-order claims are widely accepted, of course, but we can also ask more controversial questions from this internal standpoint. For instance, we might assess whether it is morally permissible to eat meat by considering moral arguments for and against meat eating. More abstractly, we might assess what it takes for an act to be just or for a person to be good. We can work on these issues together, for the internal perspective is one that moral agents share, though we may of course end up disagreeing on how to answer substantive moral questions. These will be moral disagreements.

The 'external' perspective is the point of view at which we abstract away from obviously ethical questions in order to ask metaethical questions. This metaethical perspective is usually seen as 'detached' from the first-order moral perspective, allowing occupants to remain morally neutral. ${ }^{3}$ On this standard construal, the metaethical standpoint is thus non-substantive. Here we can discuss ontological, epistemological, and semantic questions about morality without making any first-order judgements. For instance, we might ask about the content and function of moral concepts. We might ask whether and how moral properties are sewn into the fabric of reality. And we might ask whether and how we have moral knowledge. Again, these are questions that we can work on together, for the metaethical standpoint is one that anyone can occupy in reflective moments. They are also questions about which we can disagree. But such disagreements do not appear to be moral disagreements, for they are disagreements about moral discourse that appear to occur outside of moral discourse. Ronald Dworkin calls this external perspective the 'Archimedean' standpoint. ${ }^{4}$ In his words, Archimedean theories 'purport to stand outside a whole body of belief, and to judge it as a whole from premises or attitudes that owe nothing to it. ${ }^{5}$ Dworkin would see External Metaphysics as an Archimedean commitment.

Now we can state the essence of the challenge posed by Quasi-Realism and Relaxed Realism: both theories are, in a certain sense, anti-Archimedean. They deny that we can make sense of the Realist Commitments from the Archimedean standpoint that External Metaphysics putatively requires. If that's right, it appears to undermine the very possibility of Robust Realism by showing there is no way to articulate the external metaphysical 
commitments of such a theory: we will be unable to state this theory at all if External Metaphysics is shown to be false, and in this sense there will be no space for Robust Realism. Of course, this is not to suggest that antiArchimedeans are moral sceptics. Indeed, Quasi-Realists and Relaxed Realists accept Truth, Properties, Non-Reductivism, Non-Naturalism, and Mind-Independence. They just deny that these are external metaphysical claims. Moreover, it would be an oversimplification to say that the challenge consists simply in the suggestion that the Realist Commitments are nonmetaphysical. There are two ways of being anti-Archimedean, and thus two challenges with which Robust Realists are presented. We must take care to distinguish these two challenges.

One challenge is more ambitious than the other. According to the more ambitious form of the challenge:

Ambitious Anti-Archimedeanism. It is impossible to articulate an external moral ontology. This is because the external metaethical standpoint from which such an articulation would have to be made does not exist.

According to the more modest form of the challenge:

Modest Anti-Archimedeanism. It is impossible to articulate an external moral ontology. This is because, although an external metaethical standpoint exists, there is no way to make sense of the Realist Commitments at this standpoint.

These are the two main ways of denying that there is space for Robust Realism. My main topic will be the ambitious challenge, for I take it to constitute the deeper threat, but I will consider the modest challenge as well.

To clarify, Ambitious Anti-Archimedeanism constitutes a wholesale rejection of external metaethics. On this view, there is no space for metaethical theorising at all. For the Ambitious Anti-Archimedean, no external metaethical theory - including Robust Realism - can be articulated and defended or rejected. That sounds dramatic, and indeed it is, but this position is a popular one. It has attractions, and must be taken seriously. As we'll see, its appeal lies in its potential to undercut certain sceptical attacks on morality. In contrast, Modest Anti-Archimedeanism allows that there is a perspective from which we can do external metaethical theorising. To that extent, it is less dramatic than its ambitious counterpart. However, the Modest Anti-Archimedean still denies that we can interpret the Realist Commitments from an external metaethical standpoint, and this appears to threaten the possibility of articulating a robust moral ontology. I discuss Modest Anti-Archimedeanism in $\$ 3$, partly to defuse its 
threat and partly to expose the more ambitious challenge with which $\$ 4$ is concerned.

\section{Quasi-realism}

\subsection{QUASI-REALISM AND THE REALIST COMMITMENTS}

I'll start with Modest Anti-Archimedeanism, a prominent version of which can be found in Simon Blackburn's early formulation of Quasi-Realism. The debate over Quasi-Realism has developed in various ways in recent years, but Blackburn's early defence of it remains forceful and influential. Moreover, explaining the modesty of this Quasi-Realist view will help to expose the ambitious threat that is my main concern. The aim of the QuasiRealist project is to vindicate the Realist Commitments whilst showing that they come without any external metaphysical baggage. It is thus tempting to regard Quasi-Realism as a sort of 'Diet Realism,' for it purports to offer us tasty realist treats without any of the fattening metaphysics. As Blackburn puts it, Quasi-Realists attempt 'to earn, on the slender basis, the features of moral language ... which tempt people to realism. ${ }^{6}$ However, given that Quasi-Realists are often said to want to have their cake and eat it too, 'Diet Realism' is perhaps not an appropriate label after all.

So, how have Quasi-Realists sought to capture the Realist Commitments without taking on any external metaphysical baggage? First, they seek to capture Truth by going deflationary. ${ }^{7}$ According to deflationary theories of truth, the truth predicate can be eliminated from a sentence without loss of meaning. It may still play important pragmatic roles, for instance in allowing us to endorse multiple propositions without having to list all of them, but there's no semantic difference between 'it is true that $p$ ' and ' $p .{ }^{.8}$ To illustrate, the sentence 'it is true that killing is wrong' will be read as semantically equivalent to 'killing is wrong.' And 'killing is wrong' is just a first-order moral claim, the meaning of which will then have to be elaborated by the Quasi-Realist. Now, Quasi-Realism is (at least standardly) part of a package that also includes Expressivism, so Quasi-Realists will understand 'killing is wrong' as expressing a conative (rather than cognitive) attitude. ${ }^{9}$ For example, it might be suggested that 'killing is wrong' expresses disapproval of killing. On this view, the meaning of 'killing is wrong' is determined simply by the conative state of mind that the sentence serves to express. Quasi-Realists will therefore say that, correctly construed, 'it is true that killing is wrong' just expresses a first-order moral attitude.

Quasi-Realists have also sought to accommodate the commitment to Properties without any external metaphysics. For example, Blackburn suggests that there is 'no harm in saying that ethical predicates refer to properties, when such properties are merely the semantic shadows of the fact that they function 
as predicates. ${ }^{10}$ And, given that Blackburn takes moral properties to be 'semantic shadows,' he can understand such properties as irreducible and non-natural. That our moral concepts and predicates are irreducible and non-natural is something that many metaethicists now accept. This is because the 'Open Question Argument' offered by G.E. Moore is often considered to have important semantic implications, even if its external metaphysical implications have been overstated. ${ }^{11}$ Given that QuasiRealists treat properties as shadows of predicates, they can capture the commitments to both Non-Reductivism and Non-Naturalism by interpreting them at the semantic rather than the metaphysical level.

One might think it will be harder for Quasi-Realists to deliver MindIndependence because, as we've seen, Quasi-Realism is part of a package that also includes an Expressivist account of moral judgement. So it may seem obvious that Quasi-Realism makes morality dependent on our attitudes (states of approval or disapproval, for example). However, Quasi-Realists also think that Mind-Independence is correctly construed as a first-order moral commitment. This might sound puzzling at first glance, and I discuss it further in a moment, but the idea is presented by Blackburn as follows:

'[M]oral truths are mind-independent' can only summarise a list like 'If there were no people (or people with different attitudes) then $X$...' where the dots are filled in by some moral claim about $X .^{12}$

For Blackburn, Mind-Independence doesn't take us beyond first-order ethics. It's just the application of a moral judgement to worlds in which there are no people, or in which there are people with different attitudes. QuasiRealists thus construe Mind-Independence at the first-order moral level, treating it as expressing a conative attitude. It is like any other first-order claim, then, though more extravagantly put.

\subsection{QUASI-REALISM AND MODEST ANTI-ARCHIMEDEANISM}

To clarify the modesty of this anti-Archimedean challenge, let's focus on its construal of Mind-Independence. Blackburn says that the only available interpretation of Mind-Independence is a moral interpretation:

The wrongness of wanton cruelty does indeed depend on things - features of it that remind us how awful it is. But locating these is giving moral verdicts. Talk of dependency is moral talk or nothing. ${ }^{13}$

Claims about morality's putative mind-independence are made within ethics, on this view, and can only be made within ethics. There is thus no way to make sense of the attempt to adopt an external metaphysical 
construal of the commitment to Mind-Independence. In that sense, there's no space for Robust Realism.

What matters for our purposes is that this Quasi-Realist position is a form of Modest Anti-Archimedeanism rather than Ambitious Anti-Archimedeanism. Quasi-Realists are therefore only modestly anti-Archimedean, for they also accept an external metaethical theory about moral judgement. Specifically, Quasi-Realists accept Expressivism. Now, recall that Modest AntiArchimedeans don't think that the impossibility of giving a metaphysical construal of the Realist Commitments is due to the lack of an external metaethical standpoint. They have to offer some other motivation for denying us an external metaphysical reading of the Realist Commitments. And what Quasi-Realists offer is the fact that Expressivism is true at the meta-level: there can be no external metaphysical construal of the Realist Commitments because Expressivism is the true metaethical theory, and if Expressivism is the true metaethical theory then Robust Realism is not. Put another way, Expressivism is the foundation on which Quasi-Realists build their Modest Anti-Archimedean challenge.

Blackburn is explicit about this. Shortly after saying that talk of MindIndependence is moral talk or nothing, he says the following:

[T]here would be an external reading [of Mind-Independence] if realism were true. For in that case there would be a fact, a state of affairs (the wrongness of cruelty) whose rise and fall and dependency on other things could be charted. But anti-realism acknowledges no such state of affairs and no such issue of dependency. ${ }^{14}$

This is Blackburn's account of what it would take for there to be an external interpretation of Mind-Independence, and it tells us that Quasi-Realists are only able to deny that there can be such an interpretation by already accepting Expressivism at the meta-level. To maintain the attempt to articulate a robust moral ontology, then, Robust Realists must simply reject Expressivism. They can work on the basis that there is space for Robust Realism by arguing against that theory, for if Expressivism is false then it just won't be true that a metaphysical reading of Mind-Independence is unavailable.

Put another way, the real challenge to Robust Realism comes from the Expressivist part of the package rather than the Quasi-Realist part. The real challenge is thus Archimedean rather than anti-Archimedean, for it is this Archimedean theory that does the heavy lifting against a metaphysical reading of Mind-Independence. The Quasi-Realist's anti-Archimedeanism will collapse with the loss of its Expressivist foundation. That the QuasiRealist builds on an Expressivist foundation is not a new observation, but there is an interesting dialectical point here about how Robust Realists can proceed in answering Quasi-Realism. Robust Realists can defend themselves against the Quasi-Realist by doing something that they've always done, that is, by rejecting Expressivism. ${ }^{15}$ In short, Quasi-Realists won’t succeed in 
convincing you that there is no space for Robust Realism unless you're already sold on Expressivism at the meta-level, and this is something on which Robust Realists simply remain unsold. They therefore don't need any new strategic manoeuvres to respond to this modest anti-Archimedean challenge. They can just continue making arguments against the Expressivist part of its theoretical package.

Robust Realists thus shouldn't lose that much sleep over the Modest AntiArchimedean attack proposed by Quasi-Realists. This attack rests on metaethical foundations that Robust Realists can and do reject.

\subsection{TWO CAVEATS AND A LESSON}

Before examining the Ambitious Anti-Archimedeanism defended by the Relaxed Realist, it's worth stating two caveats and a lesson. The first caveat: I haven't argued that the influential version of Quasi-Realism defended in Blackburn's early work is false. I've only been arguing that its anti-Archimedean challenge is too modest to threaten the possibility of articulating a robust construal of the Realist Commitments. By permitting a metaethical standpoint from which one can argue about external metaphysics, this Modest Anti-Archimedeanism leaves space for Robust Realists to articulate and defend an external moral ontology. Robust Realism might still be false, but there is at least space for such a theory.

The second caveat: I acknowledge that there are ways of developing Quasi-Realism (and correspondingly Modest Anti-Archimedeanism) that differ from the version we've examined. Not all Quasi-Realists attempt to capture everything that might tempt someone to realism. James Dreier is sympathetic to Quasi-Realism, for example, but he attempts to identify what exactly separates the Quasi-Realist project from more robust positions. ${ }^{16}$ Even as prominent a Quasi-Realist as Allan Gibbard suggests that QuasiRealism only mimics a 'tempered' form of realism, and even then only up to a point. ${ }^{17}$ These forms of Quasi-Realism need not present themselves as a threat to the possibility of articulating a robust moral ontology. They can be tolerant of Robust Realism, allowing that it is articulable but false.

Relatedly, I've focused on Blackburn's early work. His views have developed over time, and I don't suggest that my discussion represents his current view. ${ }^{18}$ I won't go into this here, for his influential early work and the modesty of its anti-Archimedeanism are sufficient to expose where the real anti-Archimedean threat lies. Here, then, is the lesson: an anti-Archimedean threat built on an external metaethical foundation does not represent a deep challenge to the possibility of articulating a robust moral ontology, for Robust Realists can respond to such a threat by engaging with its metaethical level. It is this level at which the moment of disagreement between Robust Realists and QuasiRealists occurs. The deep anti-Archimedean threat thus comes from those who reject any such level, for they will refuse to be engaged at it. Whereas 
the Modest Anti-Archimedean threat posed by Blackburn's early QuasiRealism requires no new strategic manoeuvres from the Robust Realist, it therefore seems as though the Ambitious Anti-Archimedean threat will require some new strategic manoeuvres.

In short, the deep threat facing defenders of External Metaphysics is the ambitious rather than the modest form of the anti-Archimedean challenge. To see if there is space for Robust Realism, then, we need to consider a form of Ambitious Anti-Archimedeanism. To that end, let's examine Relaxed Realism.

\section{Relaxed realism}

\subsection{THE ATTRACTION OF RELAXED REALISM}

As the name suggests, Relaxed Realism combines a belief in the Realist Commitments with a certain lack of anxiety about the theoretical repercussions of that belief. ${ }^{19}$ Relaxed Realists are sometimes called 'Quietists,' but they tend to distance themselves from that term. They regard themselves as realists in the only feasible sense, claiming that attempts to be metaphysically robust are confused or misguided. The reason is that Relaxed Realism is a form of Ambitious AntiArchimedeanism. Whereas the Robust Realist can answer Quasi-Realists by engaging with the metaethical foundation of their theoretical package, no such response can be given against Relaxed Realists. As an Ambitious Anti-Archimedean, the Relaxed Realist specifically denies that we can occupy an external metaethical standpoint. That is, Relaxed Realists don't build on any sort of external metaethical foundation with which the Robust Realist can engage, for they reject external metaethics altogether. For the Relaxed Realist, the Realist Commitments are first-order moral claims and that's it. There's no more to be said, and attempts to give an account of the ontological status of those commitments are simply misguided. ${ }^{20}$

Initially, this line of thought may seem puzzling. But there are advantages to Relaxed Realism that can make it seem like an appealing approach to morality. ${ }^{21}$ After all, if Relaxed Realists are right then any external metaphysical doubts that you have about fitting morality into the scientific picture of the universe are entirely out of place. For the Relaxed Realist, there is simply no external metaethical standpoint from which such scepticism can make sense. Your doubts about the truth or falsity of ethical claims can thus occur only within the first-order ethical perspective, and must therefore be grounded in ordinary ethical considerations rather than external metaphysical considerations. Relaxed Realism thus has the attraction of apparently undercutting those sceptical views that appeal to 
external metaphysical doubts about a robust interpretation of the Realist Commitments. To clarify how this is meant to work, let's look at relaxed ways of interpreting the Realist Commitments.

\subsection{RELAXED REALISM AND THE REALIST COMMITMENTS}

Relaxed Realists think that normative statements constitute an autonomous domain of discourse. They propose that, just as there is an autonomous domain of mathematical discourse and an autonomous domain of scientific discourse, there is also a set of normative concepts and claims that constitutes the autonomous domain of normative discourse. For the Relaxed Realist, the correct way to construe Truth involves staying within this independent normative domain. For instance, T.M. Scanlon says that 'the truth values of statements about one domain, insofar as they do not conflict with the statements of some other domain, are properly settled by the standards of the domain they are about. ${ }^{22}$ As long as moral statements don't conflict with mathematical or scientific statements, for example, their truth is determined by the standards internal to moral domain. And these standards just consist in those first-order moral principles that we arrive at by first-order moral reasoning. As Dworkin puts it, it is a mistake to 'expect answers that step outside morality to find a nonmoral account of moral truth ... that expectation is confused: it rests on a failure to grasp the independence of morality. ${ }^{, 23}$

Relaxed Realists also interpret moral properties in a sense that requires no external metaphysics. Derek Parfit calls himself a 'non-metaphysical cognitivist,' for example, but allows that there can be normative properties in a minimal sense:

I use the word 'property' in the wide non-metaphysical sense with which we can restate any claim that is, or might be, true. Whenever someone ought to act in some way, for example, we could say either that this act has the property of being what this person ought to do, or that this person has the property of being someone who ought to act in this way. ${ }^{24}$

I'm not sure that I actually understand Parfit's non-metaphysical cognitivism, but he is apparently relaxed about accepting normative properties. He takes this to have no deep metaphysical implications.

Given their appeal to an autonomous normative domain, it's easy to see how Relaxed Realists will interpret Non-Reductivism and Non-Naturalism. Because normative statements belong to an independent domain, they won't reduce to statements from other domains. Relatedly, we needn't think that normative truths are knowable by methods appropriate for, say, the scientific domain. Normative truths are beyond the purview of the sciences, being part of a distinct domain, and are thus known by methods appropriate for that domain. Perhaps direct intuition is the appropriate method, or 
perhaps it is the method of seeking reflective equilibrium among considered judgements. ${ }^{25}$ Relaxed Realists can thus understand Non-Reductivism and Non-Naturalism in ways that remain at the first-order level.

When it comes to Mind-Independence, the Relaxed Realist once again understands this as something that can only be defended or rejected at the first-order moral level. As Thomas Nagel puts it, it is only by 'thinking about what to do and how to live' that 'we can find methods, reasons, and principles whose validity does not have to be subjectively or relativistically qualified. ${ }^{26}$ This is how Relaxed Realists seek to give a non-metaphysical construal of Mind-Independence. They think that it only makes sense as an ethical commitment, one that has to be defended by ethical arguments: thinking about what to do and how to live is first-order ethical thinking, not second-order metaphysical thinking.

It thus seems as though the Relaxed Realist can offer a construal of the Realist Commitments whilst remaining at the first-order moral level. They can give us what we want without taking on the sort of external metaphysical positions that Robust Realists think we have to accept in order to make sense of the claim that there are substantive truths about irreducible, non-natural, and mind-independent moral properties. But the Relaxed Realist doesn't just think that we can interpret the Realist Commitments at the first-order moral level. The idea is that this is the only available interpretation of them, and this is the source of the Relaxed Realist's threat to the possibility of Robust Realism.

\subsection{RELAXED REALISM AND AMBITIOUS ANTI-ARCHIMEDEANISM}

Relaxed Realism can naturally be interpreted as a form of Ambitious AntiArchimedeanism, so its threat against Robust Realism cannot be defused just by suggesting that it can be engaged at the external metaethical level. Relaxed Realists deny that there is any such level. But how can it actually be shown that this is the case? We've seen some first-order readings of the Realist Commitments, but why think that these are the only available readings? If external metaethical readings are also available to be defended or rejected, the relaxed options will seem hollow by comparison. In considering this matter I will concentrate on Dworkin's work. As Sarah McGrath puts it, Dworkin's defence of Relaxed Realism is 'undiluted and uncompromising' and therefore 'provides a useful case study' for us to examine. ${ }^{27}$

Dworkin proposes a way to test Archimedean metaethics. ${ }^{28}$ To see how this test works, consider my judgement that killing is wrong. This is straightforwardly a first-order moral judgement. But imagine that I expand on this first-order judgement, adding that it is true that killing is wrong, that wrongness is a property of killing, that this property is irreducible, non-natural, and mind-independent, that killing is really and actually wrong, and so on. Dworkin calls these the 'further claims,' and he says that there are two 
questions that we must ask about them in order to test the viability of Archimedean metaethics.

First, is there a plausible way of interpreting the further claims as moral statements? That is, can they be seen as restatements or clarifications of the original moral judgement? Second, is there a plausible way of interpreting any of the further claims as morally neutral? That is, can they be seen as Archimedean statements? Dworkin tells us that, if the answer to the first question is yes and if the answer to the second question is no, we cannot do external metaethics. Given that Robust Realism is meant as an external metaethical theory, this is a pretty serious problem for Robust Realists. If it's right, it ensures that there is no perspective from which one could possibly hope to articulate that theory.

Now, according to Dworkin the answer to the first question is indeed yes and that the answer to the second question is indeed no. Dworkin offers an affirmative answer to the first question because he thinks that that the most natural interpretation of the further claims is a moral interpretation. When someone says that a moral claim is true independently of anyone's attitudes, for example, the most natural interpretation is apparently that the individual in question is just clarifying or emphasising the content of his or her substantive moral opinion. Personally, I don't find that the most natural reading. In fact, I don't find it very natural at all. But Dworkin does, so let's accept for the sake of argument that the further claims can be read at the first-order level. That is, let's accept that the answer to the first question is yes - there is a way of interpreting the further claims as first-order moral statements.

Why is the answer to the second question $n o$ ? Dworkin says that putatively metaethical claims actually end up being moral claims themselves, or else they end up entailing moral claims:

The philosophical-sounding proposition that there are moral properties in the universe, for example, is or entails ... that some acts really are unjust, or some people really are good, or something of the sort. So read ... a skeptic who denied it would hardly be neutral toward substantive morality. ${ }^{29}$

The thought here is that, as soon as you accept that moral properties exist, you have to accept that they are instantiated in certain things. So, even an abstract claim like 'there are moral properties in the universe' is not morally neutral, and is thus not a genuinely metaethical claim. For Dworkin, then, we cannot do Archimedean metaethics. And this means that there is no space for Robust Realism: there is no metaethical perspective from which the external metaphysics of such a theory can be articulated. This leaves Relaxed Realism as the only available interpretation of the Realist Commitments.

Or does it? In the next section, I clarify the ideas that underpin this Ambitious Anti-Archimedeanism. I argue that lack of moral neutrality does not have the significance that Dworkin assumes. 


\subsection{COMPATIBILITY}

In understanding and responding to this Ambitious Anti-Archimedean challenge, it will be productive to consider the following thesis:

Compatibility. Metaethical theories are compatible with every firstorder moral theory and claim.

Note that this Compatibility thesis could be interpreted either as a hypothesis about metaethics or as a constraint on which theories count as metaethical. ${ }^{30}$ In this context it is meant to be interpreted as a constraint. According to Compatibility, a theory that fails to be compatible with every first-order moral position will thereby fail to be genuinely metaethical. Dworkin's test aims to show that no theory conforms to Compatibility. Even very abstract claims end up entailing substantive ethical positions, and supposedly metaethical theories and claims therefore end up failing to be compatible with every first-order moral position. In other words, they fail to conform to the constraint provided by Compatibility.

Compatibility lurks in the background of many influential theories. The early Emotivists, for example, were sympathetic to the idea that to do metaethics is to abstract away from first-order moral questions. A.J. Ayer says that philosophical inquiry into ethical matters should 'make no ethical pronouncements.' ${ }^{31}$ Similarly, Charles Stevenson aims to 'retain that difficult detachment which studies ethical judgements without making them. ${ }^{32}$ P.H. Nowell-Smith neatly articulates the attitude to substantive philosophical ethics implied here, saying that '[a] philosopher is not a parish priest or Universal Aunt or Citizens' Advice Bureau. ${ }^{33}$ I am not unsympathetic to that thought, for I can attest that philosophy PhD programmes are not production lines for moral saints. We'll return to this later, but the present point is that these thinkers would have been sympathetic to Compatibility. And they aren't alone. J.L. Mackie - an Error Theorist - regarded first-order ethics as distinct from metaethics, saying that 'one could be a second-order sceptic without being a first-order one, or again the other way round., 34

Nevertheless, Dworkin thinks that no putatively metaethical theory actually conforms to Compatibility. He takes this to undermine the possibility of external metaethical theorising, without which Robust Realism looks to be in some trouble. (If there is no perspective from which to articulate - let alone defend - external metaphysical readings of the Realist Commitments, that's more than a little inconvenient for those who have presenting themselves as Robust Realists about morality.) This, then, is the nub of the Ambitious Anti-Archimedean challenge posed by Dworkin. It attempts to pull the Archimedean rug from under the Robust Realist's metaphysical feet. How can this threat be answered? 
Some important responses to the Ambitious Anti-Archimedean challenge have attempted to show that it is in fact possible to make Archimedean metaethical claims that conform to Compatibility. ${ }^{35}$ This is not the sort of response that I will offer, however. Instead, I will argue that Robust Realists can reject Compatibility without thereby losing the ability to articulate and defend a robust construal of the Realist Commitments. After all, we've not been given any reason to suppose that Robust Realists are committed to Compatibility. If they were to reject this supposed constraint on what can count as a metaethical theory, would the heavens (I want to say Plato's heavens) fall? I doubt it.

In particular, I take issue with the idea that an apparently metaethical claim's merely entailing some moral claim somehow shows that it was moral all along. As we've seen, Dworkin thinks that a supposedly metaethical claim's having substantive moral bearings ensures that it is itself a substantive moral thesis. For instance, the claim that moral properties are sewn into the fabric of reality might sound as though it's non-committal on first-order matters, but it entails that 'some acts really are unjust, or some people really are good, or something of the sort. ${ }^{36}$ It is therefore not an external metaphysical claim, according to Dworkin, for it fails to conform to Compatibility. I confess that I don't get this move. How does some theory's having a substantive moral bearing make it a substantive theory?

What would the general principle be? Presumably that a claim that appears to belong to claim-kind ${ }_{1}$ actually turns out to belong to claim-kind 2 if it entails some claim that belongs to claim-kind ${ }_{2}$. But this is a peculiar principle, as one can see by looking at some examples from other contexts. Consider a certain theological claim - God created the universe in seven days - that implies a certain metaphysical claim - naturalism is false. Does the theological claim thereby fail to be theological? It seems not. Is theology just part of metaphysical discourse? I don't see it. Or consider a certain neurological claim - c-fibres are firing - that implies a certain phenomenological claim - pain is felt. Does the neurological claim thereby fail to be neurological? Does it just become phenomenological? Again, it seems not. And it would be peculiar to think that it did. In short, the idea that claims belonging to claim-kind ${ }_{1}$ actually belong to claim-kind ${ }_{2}$ given an entailment between the former and the latter seems unappealing. It's not clear to me why things should be thought different when it's metaethical claims entailing moral claims, so I don't see how such entailments undermine the idea of external metaethics.

It might be suggested that the examples just given do not involve strictly logical entailments between domains, and that this is what Relaxed Realists are interested in. However, Dworkin's own example is not a logical entailment. Recall that he offers the following comment to illustrate how putatively metaethical claims entail substantive ethical claims: 
The philosophical-sounding proposition that there are moral properties in the universe, for example, is or entails ... that some acts really are unjust, or some people really are good, or something of the sort. ${ }^{37}$

The phrase 'or something of the sort' is obviously significant here. Strictly speaking, the claim 'there are moral properties in the universe' only logically entails something like "certain aspects of the universe that can bear moral properties do in fact bear moral properties." But why should Robust Realists be unsettled by that entailment? Even if the latter claim is substantive, this seems like a reason to reject Compatibility as a constraint on external metaethics. It's not a reason to reject external metaethics itself. ${ }^{38}$

It is thus tempting to deny that Compatibility constrains what can count as metaethical. A metaethical claim may fail to be compatible with every substantive claim, but it can nevertheless be a metaethical claim. Robust Realists can thus turn the tables on Dworkin, pulling the anti-Archimedean rug from under his anti-metaphysical feet by denying that Compatibility is something to which they were ever committed in the first place. In short, they can agree that Robust Realism fails to conform to Compatibility whilst denying that this has anything like the significance that Dworkin seems to assume. Of course, in rejecting Compatibility we do not thereby lose neutrality altogether. Relaxed Realists will agree that a metaethical claim's entailing an ethical claim does not thereby mean that it cannot be compatible with other ethical claims. For instance, although the claim that moral properties are sewn into the fabric of reality implies that some acts are unjust or that some people are good (or something like that), it does not entail anything about which acts are unjust or which people are good. Nor does it tell us anything about what makes certain acts unjust or certain people good. So even if a metaethical theory fails to be compatible with every first-order claim, it can be compatible with a wide range of them.

In particular, it can be compatible with the verdicts that we arrive at when considering ordinary moral questions. To reject Compatibility is thus not to resign first-order compatibility altogether. In other words, metaethicists can reject Compatibility and instead accept something like the following:

Modest Compatibility. Most metaethical claims are compatible with a very wide range of first-order moral claims, including claims about what verdicts are correct in particular cases.

I mention this because it helps to preserve what is right about NowellSmith's observation, quoted above, according to which philosophers (metaethicists, at least) are not parish priests. Modest Compatibility captures the fact that specific moral guidance is unlikely to come from philosophical metaethics. 
After all, you'd be unlikely to consult a specialist in metaethics to find out whether eating meat is wrong. It is implausible to suppose that metaethical considerations fix a verdict on that first-order issue, and Modest Compatibility captures how metaethics does not have more practical relevance than can be taken seriously. Of course, whether or not every metaethical claim has substantive implications doesn't matter here. Perhaps, contra Dworkin, some metaethical claims succeed in being compatible with every substantive theory and claim. What matters for us is just that Compatibility doesn't constrain what counts as metaethical. In short, an external metaphysical claim might entail something at the level of first-order morality without thereby failing to be an external metaphysical claim.

The Ambitious Anti-Archimedean challenge that Dworkin poses for Robust Realists thus fails to hit the mark. Robust Realists can safely continue with their commitment to:

External Metaphysics. We can discuss the Realist Commitments from an external metaphysical standpoint, and the tenability of those commitments is to be assessed primarily from that standpoint by appeal to metaphysical argumentation.

This way of construing the Realist Commitments is not undermined by the fact that some of those commitments entail abstract claims that, on certain readings, count as substantive moral positions. In this light, the Robust Realist survives Dworkin's ambitious formulation of the anti-Archimedean challenge.

\subsection{MORAL AND METAPHYSICAL ARGUMENT}

Not every Relaxed Realist sees themselves as undermining metaethics itself. Matthew Kramer is a Relaxed Realist who thinks that metaethical theorising is a thing, but he also thinks that the class of metaethical claims is part of the class of substantive moral claims. Whereas I see the rejection of a Compatibility constraint as revealing that the distinction between metaethics and ethics exists despite entailments from the former to the latter, Kramer would see this as revealing that metaethics is actually just part of ethics.

In other words, Kramer does not see metaethics as external to ethics, but he does see it as a second-order discipline about ethics. It's just that entailments from the metaethical to the ethical show that this second-order discipline that is located within the first-order ethical domain. Again, I am not sure that I understand how this move works. To show that a metaethical claim has ethical implications is not to show that it is a part of substantive moral discourse. It seems to me a mistake to conflate these ideas. Perhaps this is partly terminological. ${ }^{39}$ It might be that some are willing to use terms 
like 'first-order' and 'moral' more expansively than others. If so, the dispute between Robust Realism and Kramer's form of Relaxed Realism is smaller than it initially looks. This would be a nice result, I think, but even if it is the case there is still an important difference between Kramer and the Robust Realist. This difference lies in how Robust Realists see arguments for the Realist Commitments unfolding.

Given his view that metaethical discourse is part of moral discourse, Kramer thinks that the Realist Commitments are to be defended or rejected primarily by appeal to substantive moral considerations. For instance, Kramer suggests that certain metaethical theories - subjectivist and relativist theories, in particular - are forced to take moral stands that expose them as untenable. ${ }^{40} \mathrm{He}$ tells us that, by making the correct moral principles constitutively dependent on our attitudes, the subjectivist must accept that the following claim would be true in (for example) a world that contained no people:

It is not the case that torturing babies for pleasure would be morally wrong.

Kramer regards this as obviously false. Given that subjectivist metaethical theories are committed to such claims, Kramer thinks that they are obviously false too. Put another way, subjectivist metaethical theories are rendered implausible by their substantive moral entailments. And the point applies generally. Kramer holds that metaethical positions are to be assessed primarily by consideration of their substantive implications, and he thinks that the Realist Commitments come out well from such an assessment.

Given their acceptance of External Metaphysics, Robust Realists deny such a crucial role to moral argument. They will say that the Realist Commitments are to be assessed primarily by appeal to external metaphysical argument, which basically involves assessing the merits of various conceptions of reality and its structure. ${ }^{41}$ In other words, metaphysical inquiry requires that we develop theoretical accounts of the various ways that reality might possibly be. We then compare these various theories by standard criteria for theory choice. In the metaethical case, it is of course moral reality that is our central concern. Robust Realists will thus say that a defender of the Realist Commitments needs to examine competing theories of moral reality in order to assess their theoretical merits.

This is a rough account of how metaphysical inquiry into the Realist Commitments can proceed. Still, as a way of arguing about moral reality it is more attractive than appeal to first-order positions. Kramer's way of arguing about moral reality is problematic. He frequently relies on the emphatic assertion of his own moral convictions when seeking to establish the Realist Commitments, condemning relativist theories, for example, by saying that they give us no way to morally criticise 'fanatical Nazis and 
Maoists and other arrant villains. ${ }^{42}$ Other metaethical views are similarly rejected because they are judged to be 'repellent,' or to have a certain 'perniciousness,' or to be 'appalling and crazy. ${ }^{43}$

I agree with Kramer's moral judgements, but I do not give them the same significance for metaethical debate. First off, it doesn't follow from the claim that metaethics is a part of ethics that ethically assessing metaethical views is the only (or even the best) way to argue about moral reality. Moreover, arguing from moral convictions is unlikely to lead to metaethical progress. After all, a critic of the Realist Commitments can reply to Kramer simply by saying that what metaphysical arguments against realism show is that, surprisingly, many moral claims that seem highly evident are in fact false (unless, say, relativistically qualified). If there's no strict division between ethics and metaethics, then arguing from metaethical to ethical positions is just as feasible as arguing from ethical to metaethical positions.

Assuming that the ethical positions to which Kramer appeals are not maximally evident, it's hard to see how his Relaxed Realists can respond without just re-asserting their personal convictions. But if that's our only available move, or even if it's meant to be our primary move, then progress seems unlikely. This way of arguing just won't be convincing to those who reject the Realist Commitments. And that's significant, if we hope that our arguments might sometimes be dialectically effective. The alternative way of proceeding gives philosophers a better shot at making progress. If one can show that a robust moral ontology is not as odd as critics find it, and if one can provide positive metaphysical arguments for accepting such an ontology, then one's case will be stronger and more likely to be dialectically effective. This is not to say that this way of arguing about moral reality will be easy, for it will bring its own challenges. Still, it has the potential to avoid real problems that arise for the Relaxed Realist's way of arguing. So, there are important differences between Robust Realism and Kramer's brand of Relaxed Realism, and I think that Robust Realists have a better approach to arguing about moral reality.

\section{Conclusion}

There is space to be a Robust Realist. We have seen no persuasive reason to think that an external metaphysical interpretation of the Realist Commitments cannot be articulated, and we have also seen that it is possible and attractive to defend or reject those commitments primarily by appeal to metaphysical rather than moral argument. None of this shows that Robust Realism is true, of course, but we can at least say that there is room to articulate and defend (or reject) a robust moral ontology. Given the Modest and Ambitious AntiArchimedean threats, this is an important victory for Robust Realism. ${ }^{44}$ 


\section{Department of Philosophy \\ University of Sheffield}

\section{NOTES}

1 Prominent defences of Quasi-Realism include: Blackburn, S. (1984). Spreading the Word. Oxford: Oxford University Press; Blackburn, S. (1993). Essays in Quasi-Realism. Oxford: Oxford University Press; Blackburn, S. (1998). Ruling Passions. Oxford: Oxford University Press; and Gibbard, A. (2003). Thinking How to Live. Cambridge, MA: Harvard University Press. Prominent defences of Relaxed Realism include: Dworkin, R. (1996). 'Objectivity and Truth: You'd Better Believe It,' Philosophy and Public Affairs 25, pp. 87-139; Dworkin, R. (2011). Justice for Hedgehogs. Cambridge, MA: Harvard University Press; Nagel, T. (1997). The Last Word. New York: Oxford University Press; Kramer, M.H. (2009). Moral Realism as a Moral Doctrine. Chichester: Wiley-Blackwell; Parfit, D. (2011). On What Matters: Volume Two. Oxford: Oxford University Press; and Scanlon, T.M. (2014), Being Realistic about Reasons. Oxford: Oxford University Press.

2 Prominent defences of Robust Realism include: Shafer-Landau, R. (2003). Moral Realism: A Defence. Oxford: Oxford University Press; FitzPatrick, W.J. (2008). 'Robust Ethical Realism, Non-Naturalism, and Normativity,' in R. Shafer-Landau (ed.) Oxford Studies in Metaethics: Volume 3. Oxford: Oxford University Press, pp. 159-205; and Enoch, D. (2011). Taking Morality Seriously: A Defence of Robust Realism. Oxford: Oxford University Press.

3 Cf. Miller, C. (2009). 'The Conditions of Moral Realism,' The Journal of Philosophical Research 34, pp. 123-155.

$4 \mathrm{He}$ is not the first to do this. For discussion, see Bloomfield, P. (2009). 'Archimedeanism and Why Metaethics Matters,' in R. Shafer-Landau (ed.) Oxford Studies in Metaethics: Volume 4. Oxford: Oxford University Press, p. 285.

5 Dworkin, 1996, p. 88

6 Blackburn, 1984, p. 171

7 Cf. Blackburn, S. (1996). 'Securing the Nots: Moral Epistemology for the Quasi-Realist,' in W. Sinnott-Armstrong and M. Timmons (eds) Moral Knowledge? New Readings in Moral Epistemology. New York: Oxford University Press, p. 86; and Blackburn, 1998, pp. 78-79.

8 It is important to deflationists that the truth predicate plays some pragmatic role, for otherwise it would not be clear why we actually have it in the first place. The idea that it allows us to endorse multiple propositions at once is illustrated by cases like 'everything Alice said in her presentation is true.' Without the truth predicate, we'd presumably have to just list and endorse everything that Alice said in her presentation - an arduous task.

9 I say 'standardly,' because it's possible that one could attach a different meta-level theory of moral judgement to Quasi-Realism. So perhaps Quasi-Realists don't have to be Expressivists. But they do have to build on some meta-level alternative to Robust Realism, otherwise they'll just be Ambitious Anti-Archimedeans. Expressivism is the standard choice.

10 Blackburn, 1993, p. 181.

11 For the original statement of the Open Question Argument, see Moore, G.E. (1903). Principia Ethica. Cambridge: Cambridge University Press, ch. 1. For discussion of its having semantic rather than metaphysical implications, see Gibbard, A. (2002). 'Knowing What to Do, Seeing What to Do,' in P. Stratton-Lake (ed.) Ethical Intuitionism: Re-evaluations. Oxford: Oxford University Press, pp. 212-228.

12 Blackburn, 1998, p. 311.

13 Blackburn, 1993, p. 173, my emphasis.

14 Blackburn, 1993, p. 173. 
15 Note that anti-realist critics of Expressivism can invert this response by saying that QuasiRealists inherit Robust Realism's problems. A nice version of this approach can be found in Street, S. (2011). 'Mind-Independence Without the Mystery: Why Quasi-Realists Can't Have It Both Ways,' in R. Shafer-Landau (ed.) Oxford Studies in Metaethics: Volume 6. Oxford: Oxford University Press, pp. 1-32.

16 Dreier, J. (2004). 'Meta-ethics and the Problem of Creeping Minimalism,' Philosophical Perspectives 18, pp. 23-44.

17 Gibbard, A. (2011). 'How Much Realism? Evolved Thinkers and Normative Concepts,' in R. Shafer-Landau (ed.) Oxford Studies in Metaethics: Volume 6. Oxford: Oxford University Press, pp. 33-51. Gibbard (p. 44) describes Dworkin as a tempered realist, so perhaps what he calls 'tempered realism' is just what I call 'Relaxed Realism.'

18 Cf. Blackburn, S. (2010). 'Truth, Beauty, and Goodness,' in R. Shafer-Landau (ed.) Oxford Studies in Metaethics: Volume 5. Oxford: Oxford University Press, pp. 295-314; and Blackburn, S. (2010). 'The Majesty of Reason,' Philosophy 85, pp. 5-27.

19 Cf. McGrath (2014). 'Relax? Don't Do It! Why Moral Realism Won't Come Cheap,' in R. Shafer-Landau (ed.), Oxford Studies in Metaethics: Volume 9. Oxford: Oxford University Press, p. 187.

${ }^{20}$ This is why some label the view 'Quietism.' I avoid this term because it is regarded as misrepresentative by those to whom it is applied. 'Relaxed Realism' is a term that others have used, and it is a nice one.

21 Cf. McPherson, T. (2011). 'Against Quietist Normative Realism,' Philosophical Studies 154, p. 238

22 Scanlon, 2014, p. 19.

23 Dworkin, 2011, p. 38

24 Parfit, 2011, p. 756.

25 For a direct intuition approach, see Parfit, 2011, ch. 32. For a reflective equilibrium approach, see Scanlon, 2014, ch. 4.

26 Nagel, 1997, p. 102.

27 McGrath, 2014, p. 187

28 Dworkin, 1996, pp. 96-97.

29 Ibid., p. 100. Note that in its original context, Dworkin is claiming here that this 'philosophical-sounding proposition' entails a denial of global internal scepticism. It does this by ensuring that there are moral properties instantiated in certain entities.

30 Cf. McPherson, T. (2008). 'Metaethics and the Autonomy of Morality,' Philosophers' Imprint 8, p. 3.

31 Ayer, A.J. (2001) [1936]. Language, Truth and Logic. Harmondsworth: Penguin, p. 105.

32 Stevenson, C.L. (1944). Ethics and Language. New Haven, CT: Yale University Press, p. 110

33 Nowell Smith, P.H. 1954. Ethics. Harmondsworth: Penguin, p. 12.

34 Mackie, J.L. (1977). Ethics: Inventing Right and Wrong. Harmondsworth: Penguin, p. 16. Something like Compatibility seems important to many Error Theorists, because they many of them want to avoid their nihilistic conclusions at the second-order level having implications for how we live our lives. I discuss what Error Theorists can say about first-order matters in Ingram, S. (2015). 'After Moral Error Theory, After Moral Realism,' The Southern Journal of Philosophy 53(2), pp. 227-248.

35 Cf. Dreier, J. (2002). 'Metaethics and Normative Commitment,' Philosophical Issues 12, pp. 241-263; and Ehrenberg, K.M. (2008). 'Archimedean Metaethics Defended,' Metaphilosophy 39, pp. 508-529.

36 Dworkin, 1996, p. 100.

37 Ibid.

38 It may be that the phrase 'or something of the sort' is used here to suggest an open-ended disjunction, in which case Dworkin is making a (less than clear) version of the claim that the 
philosophical-sounding proposition entails something like something like 'certain aspects of the universe that can bear moral properties do in fact bear moral properties.' But my point still stands - the Robust Realist need not be unsettled by that entailment.

39 Cf. Enoch, 2011, p. 130.

40 Kramer, 2009, pp. 30-35.

41 For more details on this approach to metaphysical argument, see Lowe, E.J. (1998). The Possibility of Metaphysics. Oxford: Oxford University Press.

42 Kramer, 2009, p. 45.

43 Ibid., p. 32, p. 33, and p. 133.

44 Earlier versions of this paper received helpful comments from Jimmy Lenman, Miranda Fricker, Graham Bex-Priestley, Matthew Kramer, and an audience at the University of Manchester. I am grateful to them. I am also grateful to Lizzy Kirkham, Shirley Carter, and Denise Fox. This article was written during an AHRC doctoral scholarship. 